\title{
Female infertility and laparoscopic surgery: A series of 415 operations at the Yaounde Gyneco-Obstetric and Pediatric Hospital, Cameroon
}

\author{
Emile Telesphore Mboudou ${ }^{1,2}$, Pascal Foumane $e^{1,2^{*}}$, Frederick Lifang-Ikomi Morfaw ${ }^{1,2}$, \\ Jacqueline Ze Minkande $^{3}$, Julius Sama Dohbit ${ }^{1,2}$, Bernard Armand Enama Mbatsogo ${ }^{2}$ \\ ${ }^{1}$ Department of Obstetrics and Gynecology, Faculty of Medicine and Biomedical Sciences (FMBS), The University of Yaoundé 1 , \\ Yaoundé, Cameroon \\ ${ }^{2}$ Department of Obstetrics and Gynecology, Yaoundé Gyneco-Obstetric and Pediatric Hospital, Yaoundé, Cameroon \\ ${ }^{3}$ Department of Anesthesiology and Reanimation, Yaoundé Gyneco-Obstetric and Pediatric Hospital, Yaoundé, Cameroon \\ Email: "pfoumane2004@yahoo.fr.
}

Received 13 October 2013; revised 6 November 2013; accepted 14 November 2013

Copyright (c) 2013 Emile Telesphore Mboudou et al. This is an open access article distributed under the Creative Commons Attribution License, which permits unrestricted use, distribution, and reproduction in any medium, provided the original work is properly cited.

\begin{abstract}
Objective: To describe the practice of laparoscopic surgery in the treatment of infertility at the Yaoundé Gyneco-Obstetrics and Pediatric Hospital. Materials and Methods: This was an observational study with retrolective data collection. All patients who underwent laparoscopy for infertility with a complete file were recruited. Data were collected on a pre-established form and analyzed with Microsoft Excel 2007 software. Results: Six hundred and thirty-three women, representing $6.9 \%$ of gynecologic operations, underwent laparoscopic surgery during the study period. Infertility accounted for $69.8 \%$ (442 cases) of the indications. Four hundred and fifteen files were analyzed. The commonest intraoperative findings were: tubo-peritoneal adhesions (71.6\%), hydrosalpinx with distal tubal occlusion (41.5\%), peri-hepatic adhesions (22.4\%), uterine fibroids $(20.2 \%)$ and tubal phimosis (14.0\%). Adhesiolysis, neosalpingostomy and fimbrioplasty were the commonest surgical gestures. At the end of the procedure, the best tube was staged as favorable in $\mathbf{5 7 . 6 \%}$ of our patients. A complication rate of $\mathbf{4 . 3 \%}$ was observed. Conclusion: Infertility is the main indication for laparoscopic surgery in our setting. The main operative findings are tubo-peritoneal adhesions and hydrosalpinx. The most practiced tubal surgical gesture is neosalpingostomy. Half of the recruited women have a favorable stage for the best tube. The complication rate is low.
\end{abstract}

${ }^{*}$ Corresponding author.
Keywords: Infertility; Laparoscopic Surgery; Tubal Surgery; Yaoundé; Cameroon

\section{INTRODUCTION}

Since gynecological laparoscopic surgery was introduced in Cameroon [1], several studies have been dedicated to this new surgical approach in our setting [1-7]. Even though laparoscopic operations in gynecology now include a variety of surgeries previously done only by laparotomy such as the cure of uterine prolapse, simple or radical hysterectomy and pelvic or para-aortic lymphadenectomy [8], it remains mainly limited to tuboadnexal surgery in Cameroon. Raiga et al. have reported a series of 735 gynecological laparoscopic surgeries after five years of practice in Cameroun, most of which were indicted for tubal infertility [2]. In the same hospital, Kasia et al. have documented 194 tubal surgeries by laparoscopy with a pregnancy rate of $27.3 \%$ [3]. Afterwards, the laparoscopic surgical rate of tubal surgery of 91.3\% has been reported in the same setting [4]. At the same time, advanced laparoscopic surgeries have only been documented by Belley Priso et al. in Douala and Kasia et al. in Yaoundé [5-6].

The Yaoundé Gyneco-Obstetric and Pediatric Hospital was created in 2002 and a study by Foumane et al. has stated a laparoscopic rate of $6.7 \%$ for the management of ectopic pregnancy [7]. Thus, little is known concerning the practice of laparoscopic surgery for tubal surgery in this hospital, especially when female infertility is suspected.

The objective of this study was to describe the practice 
of laparoscopic surgery in the management of female infertility at the Yaoundé Gyneco-Obstetric and Pediatric Hospital, Cameroon. This study would determine the role of tubal surgery for infertility in our surgical activity and provide data on surgical findings as well as complications observed.

\section{METHODOLOGY}

It was an observational study with a retrolective data collection, carried out at the Yaoundé Gyneco-Obstetric and Pediatric Hospital, Cameroon. After the authorization of the hospital authorities was obtained, all the female patients laparoscopically operated for infertility from January $1^{\text {st }} 2004$ to November $30^{\text {th }} 2011$ were included. Patients with incomplete files were excluded. The studied variables were: age, parity, type of infertility, hysterosalpingography results, operatory findings, operatory gestures, quality of the best tube accordingly to Mage's tubal score [9], complications observed. Data were analyzed using Microsoft Excel 2007.

\section{RESULTS}

During the study period, 9194 gynecological surgeries were carried out at the Yaoundé Gyneco-Obstetric and Pediatric Hospital. Among these, 633 were done by laparoscopy, giving an endoscopic surgery rate of $6.9 \%$. At the same time, $69.8 \%$ (442/633) of the laparoscopic operations performed were indicated for infertility. Twentyseven files were incomplete (27/442; 6.1\%) and our analysis was done on the remaining 415 files (93.9\%).

The mean age of our patients was $31.8 \pm 4.9$ years with a range from 17 to 47 years. Most of the women (349/415; 84.1\%) were aged between 25 and 39 years. Nearly three quarters of the included patients were married (301/415; 72.5\%), while $85.3 \%$ of them (354/415) had at least a secondary education level. Half of the operated women (209/415; 50.4\%) had an income and $94.0 \%$ of them were living in an urban area (Table 1).

Even though $72.7 \%$ (202/415) of the infertile women have previously been pregnant in their life, only $37.6 \%$ (156/415) have experienced a delivery and 25.5\% (106/ 415) have delivered once. Most of them (365/415; 87.9\%) were pauciparous (Table 2). On the 415 recruited patients, $40(9.6 \%)$ had a pelvic surgical history, ectopic pregnancy being encountered in $72.5 \%$ (29/40) of the cases (Figure 1).

Tubo-peritoneal adhesions were present in $71.6 \%$ (297/415) of the operated patients. Hydrosalpinx with distal tubal occlusion was encountered in 41.5\% (172/ 415 ) of our patients while proximal tubal occlusion concerned $2.4 \%(10 / 415)$ of the cases. Tubal phimosis was described in $14.0 \%$ (58/415) cases. Peri-hepatic adhesions and fibroid were respectively discovered during
Table 1. Socio-demographic variables of women operated for infertility $(n=415)$.

\begin{tabular}{|c|c|c|}
\hline Variables & Frequency & $\%$ \\
\hline \multicolumn{3}{|l|}{ Age (years) } \\
\hline $15-20$ & 1 & 0.2 \\
\hline $20-25$ & 30 & 7.2 \\
\hline $25-30$ & 81 & 19.5 \\
\hline $30-35$ & 176 & 42.4 \\
\hline $35-40$ & 92 & 22.2 \\
\hline $40-45$ & 33 & 8.0 \\
\hline$>45$ & 2 & 0.5 \\
\hline \multicolumn{3}{|l|}{ Marital status } \\
\hline Single & 101 & 24.3 \\
\hline Married & 301 & 72.5 \\
\hline Cohabitation & 13 & 3.1 \\
\hline \multicolumn{3}{|l|}{ Education } \\
\hline None & 2 & 0.5 \\
\hline Primary & 59 & 14.2 \\
\hline Secondary & 164 & 39.5 \\
\hline University & 190 & 45.8 \\
\hline \multicolumn{3}{|l|}{ Profession } \\
\hline Housewife & 178 & 42.9 \\
\hline Student & 28 & 6.7 \\
\hline Self employment & 78 & 18.8 \\
\hline Civil servant & 68 & 16.4 \\
\hline Private sector worker & 63 & 15.2 \\
\hline \multicolumn{3}{|l|}{ Residency area } \\
\hline Rural & 24 & 5.8 \\
\hline Urban & 390 & 94.0 \\
\hline Abroad & 1 & 0.2 \\
\hline
\end{tabular}

Table 2. Gravidity and parity of operated patients $(n=415)$

\begin{tabular}{ccc}
\hline Variable & Frequency & \% \\
\hline Gravidity & 113 & \\
0 & 130 & 27.3 \\
1 & 172 & 31.3 \\
2 and more & & 41.4 \\
Parity & 259 & \\
0 & 106 & 62.4 \\
1 & 50 & 25.5 \\
2 and more & 12.1 \\
\hline
\end{tabular}




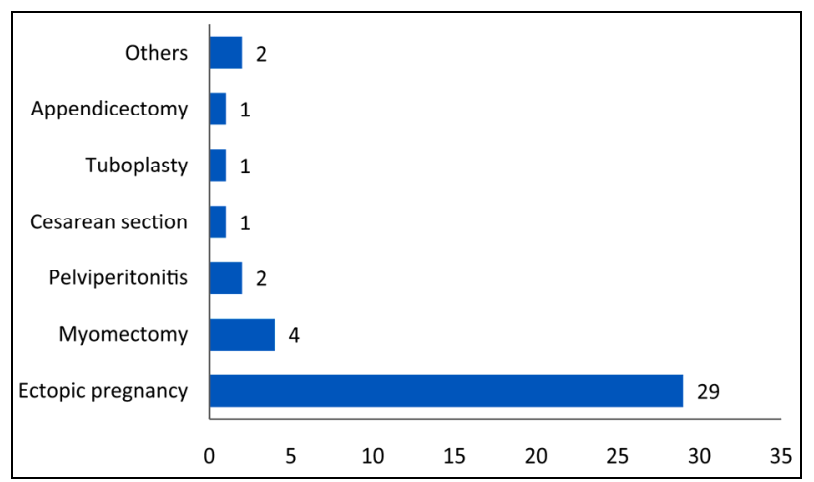

Figure 1. Past pelvic surgical events reported $(n=40)$.

laparoscopy in 22.4\% (93/415) and 20.2\% (84/415) of the patients (Table 3).

The commonest operatory gestures during laparoscopic surgery included adhesiolysis (297/415; 71.6\%), neosalpingostomy with fimbriae eversion $(172 / 415 ; 41.5)$ and fimbrioplasty (58/415; 14.0\%). Tubal scores 1 and 2 were reported in $57.6 \%(239 / 415)$ patients, while $42.4 \%$ $(176 / 415)$ of them had a tubal score 3 or 4 for the best tube at the end of surgery (Table 4).

According to the analyzed files, 18 patients (4.3\%) presented operatory complications, the commonest described being uterine perforation (Table 5).

\section{DISCUSSION}

The $6.9 \%$ rate of endoscopic surgery in gynecology found in this setting remains below the figures published by well trained and equipped teams like that of Takacs et al. who reported a laparoscopically treatment rate of 86.3\% for ectopic pregnancy since 2004 in Miami, USA [10]. This rate usually depends on socio-cultural, economic and structural conditions, explaining similar figures in similar settings. In the same department, a $6.7 \%$ rate of ectopic pregnancy management by laparoscopy has been reported [7]. Though a closer figure of $10 \%$ has been documented in the neighboring Gabon by Pither $e t$ al. [11], Sanogo et al. have published a surprising 19\% rate of endoscopic surgery in Bamako [12], suggesting that the figures could be improved, even in a Sub-Saharan Africa setting.

Most of our laparoscopic surgeries are indicated for infertility (69.8\%). This figure is similar to the $76.3 \%$ of laparoscopic operations for infertility reported in 2007 by Mboudou et al. at the Yaoundé General Hospital [13], and remains beyond the rates observed in western countries where the prevalence of pelvic infections is low and access to assisted reproduction therapy easier [14].

The sociodemographic characteristics of our patients are similar to those of infertile women reported in the same setting. We found a mean age of 31.8 years in our patients while Belley Priso et al. in the Douala General
Table 3. Laparoscopic findings in operated patients $(n=415)$.

\begin{tabular}{|c|c|c|}
\hline Findings & Frequency & $\%$ \\
\hline \multicolumn{3}{|l|}{ Tubal } \\
\hline Tubo-peritoneal adhesions & 297 & 71.6 \\
\hline Unilateral hydrosalpinx & 77 & 18.6 \\
\hline Bilateral hydrosalpinx & 95 & 22.9 \\
\hline Unilateral pyosalpinx & 8 & 1.9 \\
\hline Bilateral pyosalpinx & 1 & 0.2 \\
\hline Unilateral proximal occlusion & 6 & 1.4 \\
\hline Bilateral proximal occlusion & 4 & 1.0 \\
\hline Tubal phimosis & 58 & 13.7 \\
\hline Erected tube & 7 & 1.7 \\
\hline Paratubal cyst & 31 & 7.5 \\
\hline \multicolumn{3}{|l|}{ Ovarian } \\
\hline Ovarian cyst & 40 & 9.6 \\
\hline Polycystic ovaries & 38 & 9.2 \\
\hline \multicolumn{3}{|l|}{ Uterine } \\
\hline Uterine fibroids & 84 & 20.2 \\
\hline Malformations & 3 & 0.7 \\
\hline \multicolumn{3}{|l|}{ Pelvic } \\
\hline Endometriosis & 21 & 5.0 \\
\hline Normal pelvis & 7 & 1.7 \\
\hline \multicolumn{3}{|l|}{ Liver } \\
\hline Peri-hepatic adhesions & 93 & 22.4 \\
\hline Others & 18 & 4.3 \\
\hline
\end{tabular}

Table 4. Mage's score of the best tube following surgery ( $n=$ 415).

\begin{tabular}{ccc}
\hline Score & Frequency & \% \\
\hline 1 & 60 & 14.5 \\
2 & 179 & 43.1 \\
3 & 123 & 29.6 \\
4 & 53 & 12.8 \\
Total & $\mathbf{4 1 5}$ & $\mathbf{1 0 0 . 0}$ \\
\hline
\end{tabular}

Hospital [15] and Nana et al. in the Yaoundé Central Hospital [16] respectively published a mean age of 32 and 32.7 years. At the same time, $87.9 \%$ of the operated women in our series were pauciparous. This figure is similar to the $93.5 \%$ pauciparous women found by Mboudou et al. at the Yaoundé General Hospital [13].

Nearly three quarters of women with a pelvic surgical history had been operated for ectopic pregnancy. This is different from the findings of Nzintcheu et al. [17] who 
Table 5. Complications observed following surgery $(n=415)$.

\begin{tabular}{ccc}
\hline Complications & Frequency & \% \\
\hline Per-operatory & 405 & 97.6 \\
None & & \\
Serious complications & 3 & 0.7 \\
Intestine perforation & 3 & 0.7 \\
Vascular lesion with massive hemorrhage & 4 & 1.0 \\
Uterine perforation & $/$ & $/$ \\
Minor complications & & \\
Post-operatory & 407 & 98.2 \\
None & & \\
Serious complications & 1 & 0.2 \\
Pelviperitonitis & 1 & 0.2 \\
Eventration at incision site & & \\
Minor complications & 1 & 0.2 \\
Parietal bleeding & 3 & 0.7 \\
Pelvic pain & 2 & 0.5 \\
Epigastralgia & & \\
\hline & &
\end{tabular}

reported myomectomy as the commonest pelvic surgical past event encountered in infertile women undergoing laparoscopy. This difference can find an explanation in the fact that Nzintcheu et al. did a prolective data collection, while we collected our data retrolectively. A past history of myomectomy could be under-reported in the patients files. On the other hand, ectopic pregnancy and infertility share several risk factors and are commonly associated.

Tubo-peritoneal adhesions, hydrosalpinx, fibroids and peri-hepatic adhesions are the commonest laparoscopic findings in our series. The role of tubo-peritoneal adhesions and hydrosalpinx in female infertility is well documented [18,19]. Apart from pelvic infections due to Chlamydiae trachomatis and others pathogens [19], adhesions may arise following pelvic surgery or unsafe abortion which are common in our setting [15]. As well as pelvic adhesions, peri-hepatic adhesions result from pelvic inflammatory diseases. They have been found in $40 \%$ of infertile women in the same setting and their findings were correlated to the presence of severe tubal lesions [17].

According to the Mage's classification, the tubal score was favorable in $57.6 \%$ of our patients. This figure is not far from the $46.1 \%$ reported by Nzintcheu et al. in the same hospital in 2009 following a prolective data collection on 130 infertile women [17]. The scoring of the best tube at the end of laparoscopic surgery for infertility remains an important step in low-resource settings with low access to assisted reproductive therapy [3].
Our complications rate of $4.3 \%$ is beyond the rate found by Mboudou et al. at the Yaoundé General Hospital in a group of 609 patients operated by laparoscopy [13]. However, they faced a set of diversified indications, including two cases of laparoscopic hysterectomies.

Our results should be considered with some limitations inherent to a study with rétrolective data collection. Twenty-seven patients with incomplete files were excluded. At the same time, the collection of data such as complications could have been non exhaustive, serious complications tending to be more reported than minor. All these might have given some bias to our results.

\section{CONCLUSIONS}

Infertility is the main indication for laparoscopic surgery in our setting. The main operative findings are tuboperitoneal adhesions and hydrosalpinx. Ectopic pregnancy is the most common past pelvic surgical event reported. The most practiced surgical gestures are adhesiolysis, neosalpingostomy and fimbrioplasty. Half of the recruited women have a favorable stage for the best tube. The complication rate is low.

We recommend a strengthening of endoscopic surgical skills of the gynecologists engaged in the practice of laparoscopic surgery in advanced techniques, as well as the update of the available equipments at the Yaoundé Gyneco-Obstetric and Pediatric Hospital.

\section{REFERENCES}

[1] Raiga, J., Kasia, J.M., Canis, M., Glowaczower, E., Doh, A. and Bruhat, M.A. (1994) Introduction of gynecologic endoscopic surgery in an African setting. International Journal of Gynecology \& Obstetrics, 46, 261-264. http://dx.doi.org/10.1016/0020-7292(94)90403-0

[2] Raiga, J., Kasia, J.M. and Bruhat, M.A. (1999) Laparoscopic surgery in the Cameroon. International Journal of Gynecology \& Obstetrics, 65, 65-66. http://dx.doi.org/10.1016/S0020-7292(98)00206-9

[3] Kasia, J.M., Raiga, J., Doh, A.S., Biouele, J.M., Pouly, J.L., Kwiatkowski, F., et al. (1997) Laparoscopic fimbrioplasty and neosalpingostomy. Experience of the Yaoundé General Hospital, Cameroon (report of 194 cases). The European Journal of Obstetrics \& Gynecology and Reproductive Biology, 73, 71-77. http://dx.doi.org/10.1016/S0301-2115(96)02674-7

[4] Tchente Nguefack, C., Mboudou, E., Tejiokem, M.C. and Doh, A. (2009) Complications of endoscopic surgery at the Gynecologie B department of the Yaoundé General Hospital, Cameroon. Journal de Gynécologie Obstétrique et Biologie de la Reproduction, 38, 545-551. Frenchhttp://dx.doi.org/10.1016/j.jgyn.2009.06.008

[5] Belley Priso, E., Mboudou, E., Nana Njamen, T., Egbe Obichemti, T. and Doh, A.S. (2009) Total hysterectomy by laparoscopy: The experience of Douala General Hos- 
pital. Clinics in Mother and Child Health, 6, 1135-1138.

[6] Kasia, J.M., Nana Njamen, T., Raiga, J., Calmelet, P., Medou, A., Messina, R., et al. (2006) Laparoscopic hysterectomy in Africa: A series of 48 cases. Journal of SAGO, 7, 26-30.

[7] Foumane, P., Mboudou, E.T., Dohbit, J.S., Mbakop Ndingue, S., Tebeu, P.M. and Doh, A.S. (2011) Conservative treatment of ectopic pregnancy in a sub-Saharan African setting. Tropical Doctor, 41, 79-81. http://dx.doi.org/10.1258/td.2011.100085

[8] Querleu, D., Leblanc, E., Ferron, G. and Narducci, F. (2006) Laparoscopic surgery in gynaecological oncology. European Journal of Surgical Oncology, 32, 853-858. http://dx.doi.org/10.1016/j.ejso.2006.03.043

[9] Mage, G., Pouly, J.L., de Jolinière, J.B., Chabrand, S., Riouallon, A. and Bruhat, M.A. (1986) A preoperative classification to predict the intrauterine and ectopic pregnancy rates after distal tubal microsurgery. Fertility and Sterility, 46, 807-810.

[10] Takacs, P. and Chakhtoura, N. (2006) Laparotomy to laparoscopy: changing trends in the surgical management of ectopic pregnancy in a tertiary care teaching hospital. Journal of Minimally Invasive Gynecology, 13, 175-177. http://dx.doi.org/10.1016/j.jmig.2006.01.007

[11] Pither, S., Mayi Tsonga, S., Mandji, J.M., Ndombi Onnas, I., Ogowet Igumu, N. and Kasia, J.M. (2007) Gynecological laparoscopic surgery in Libreville: Centre hospitalier de Libreville-experience on 341 cases. Médecine d'Afrique Noire, 54, 94-97.

[12] Sanogo, Z.Z., Yena, S., Doumbia, D., Ouattara, M.O., Koita, A.K., Sidibé, S., et al. (2007) Assessment of 45 months of laparoscopic surgery activity in Bamako. Mali Médical, 22, 47-51.

[13] Mboudou, E.T., Ze Minkande, J., Eyenga, V.C., Foumane,
P., Tchente, N.C. and Doh, A.S. (2007) The complications of laparoscopic surgery at the Yaoundé General Hospital, Cameroon. Revue Africaine d'Anesthésiologie et de Médecine d'Urgence, 12, 18-26.

[14] Practice Committee of the American Society for Reproductive Medicine (2012) Committee opinion: Role of tubal surgery in the era of assisted reproductive technology. Fertility and Sterility, 97, 539-545. http://dx.doi.org/10.1016/j.fertnstert.2011.12.031

[15] Belley Priso, E., Mboudou, E., Gonsu Kamga, H., Nana Njamen, T. and Doh, A.S. (2009) Risk factors of female infertility at the Douala General Hospital. Journal Africain d'Imagerie Médicale, 10, 227-233.

[16] Nana, P.N., Wandji, J.C., Fomulu, J.N., Mbu, R.E., Leke, R.J.I. and Woubinwou, M.J. (2011) Psycho-social aspects in infertile patients at the Central Maternity of the Yaoundé Central Hospital, Cameroon. Clinics in Mother and Child Health, 8, 5 p. http://dx.doi.org/10.4303/cmch/C100601

[17] Nzintcheu Youssa, J.M., Foumane, P., Mboudou, E.T., Nana, P.N., Fomulu, J.N. and Doh, A.S. (2012) Perihepatitis as a laparoscopic finding in infertile women at the Yaoundé Gyneco-Obstetric and Pediatric Hospital: Prevalence et correlation with tubo-pelvic lesions. Clinics in Mother and Child Health, 9, 5 p. http://dx.doi.org/10.4303/cmch/C120501

[18] Marana, R., Ferrari, S., Merola, A., Astorri, A.L., Pompa, G., Milardi, D., et al. (2011) Role of a mini-invasive approach in the diagnosis and treatment of tubo-peritoneal infertility as an altenative to IVF. Minerva Ginecologica, 63, 1-10.

[19] Muzii, L., Sereni, M.I., Battista, C., Zullo, M.A., Tambone, V. and Angioli, R. (2010) Tubo-peritoneal factor of infertility: Diagnosis and treatment. Clinical Therapeutics, 161, 77-85. 